\title{
Enterohemorrhagic Escherichia coli (EHEC) in water from karst springs: detection with real-time PCR and isolation of strains
}

\author{
Andreas Baumgartner ${ }^{1} \cdot$ Isabel Niederhauser $^{1} \cdot$ David Diston $^{2} \cdot$ \\ Dominik Moor ${ }^{1}$
}

Received: 16 September 2016/Accepted: 5 October 2016/Published online: 18 October 2016 (c) The Author(s) 2016. This article is published with open access at Springerlink.com

\begin{abstract}
Within 2 months, two water sources in a karst area in Switzerland were sampled 9 times each, and analyzed by real-time PCR for 6 EHEC O-types, Shiga-like-toxin (stx 1 and stx2) and intimin (eae) genes. With the exception of 0111, 5 O-types were recorded regularly and at high frequencies (O26: $33.3 \%$; 0157: 33.3 \%; O104: 66.6 \%; 0103: $72.2 \%$; O145: $94.4 \%$ ). Genes for Shiga-like-toxins and intimin were almost omnipresent (stx1: 77.8 \%; stx2: $83.3 \%$; eae: $77.8 \%$ ). Strain isolation was undertaken for O-groups 26, 103, 104, 145 and 157. Sample selection for strain isolation was based on Cq-values for the O-groups and stx1, stx2 and eae. From selected samples, frozen enrichment cultures were cultivated on EHLY-agar and 50 typical colonies screened for the O-type and genes encoding for $s t x 1, s t x 2$ and eae. With this approach, only one virulent EHEC-strain could be isolated (Escherichia coli 0103, stx1 +; stx 2 -; eae +). We carried out one extensive testing with 800 colonies of O-group 0145, and no virulent strain was isolated. Our findings showed that PCR-results are not sufficient to formulate epidemiological conclusions and that the isolation of strains is necessary. However, as the detection procedure of EHEC in foods is cumbersome and expensive, the appropriateness of such an approach in official food control is a matter of debate.
\end{abstract}

Dominik Moor

dominik.moor@blv.admin.ch

1 Swiss Federal Food Safety and Veterinary Office FSVO, 3003 Bern, Switzerland

2 Swiss Federal Institute of Aquatic Science and Technology, 8600 Dübendorf, Switzerland
Keywords EHEC - Official method . Microbiological criteria · Virulent strains . Water contamination

\section{Introduction}

In 1992, Enterohemorrhagic Escherichia coli (EHEC) was described for first time when cases of bloody diarrhea were observed after the consumption of undercooked hamburgers in the U.S. The causative agent in this first EHEC-outbreak was the strain O157:H7 EDL933 (O’Brien et al. 1993). In Switzerland, EHEC infections have been registered since 1999 with the annual number of cases being low (between 30 and 70). Since the initiation of mandatory registration, noteworthy EHEC outbreaks have not been reported; only a small outbreak in 2005 was observed owing to contamination of drinking water with fecal material of bovine origin after a heavy rainfall event (Bundesamt für Gesundheit 2008). However, in 2015 a significant increase of cases was reported. The reason behind this increase is not fully elucidated, but there is evidence that suggest that the introduction of multiplex PCR assays for gastrointestinal agents in diagnostic laboratories may be responsible (Bundesamt für Gesundheit 2015).

For the transmission of EHEC to humans, meat and meat-products are the main risk factors. However, there are also outbreaks known due to contaminated foods of plant origin such as sprouts. A spectacular outbreak with thousands of infected persons occurred 1996 in Japan with epidemiological evidence showing that radish sprouts were the most probable origin of infection (Michino et al. 1999). In 2011, again 
sprouts were responsible in an outbreak in Germany. After consumption of contaminated fenugreek, 3842 infections due to an EHEC-strain of serotype 0104:H4 were reported (2897 cases of gastroenteritis; 855 cases of hemolytic uremic syndrome, HUS with 53 fatalities) (Robert Koch Institute 2011). Consequently, the responsible authorities of the EU decreed a microbiological criterion for EHEC in sprouts, which Switzerland has adopted in the Ordinance on Hygiene (Eidgenössisches Departement des Innern 2014). This criterion states that EHEC serotypes O26, 0103, 0104, O111, 0145 and 0157 should not be detectable in 25 grams of sample after enrichment. According to the EU, testing must be done using the reference method ISO/TS 13136:2011 and a method of the European reference laboratory for $E$. coli. PCR is used to screen for the target serotypes and virulence factors. If positive, EHEC-strains must also be isolated. Isolation is needed to confirm PCR result and also to have strains for epidemiological typing. In the present study, raw water samples from microbiologically vulnerable sources were tested for the presence of EHEC using the recommended EU method. Difficulties and challenges in connection with the screening and with the isolation of strains are also presented and discussed here.

\section{Methods and materials}

\subsection{Collection and processing of water samples}

Two karst sources with reported elevated bacterial counts in the St. Imier valley (Canton Bern, Switzerland) were sampled 9 times each between September and October 2014. Samples were collected in sterile $1 \mathrm{l}$ glass Schott bottles, placed in a cool-box and transported to the FSVO laboratories within $2 \mathrm{~h}$ of collection. Depending on filterability of the sample, either $500 \mathrm{ml}$ (source A) or $1000 \mathrm{ml}$ (source B) was filtered through a $0.45 \mu \mathrm{m}$ pore size membrane (Millipore, HAWG047S6).

\subsection{Enrichment of EHEC}

The filters were transferred into $15 \mathrm{ml}$ Falcon tubes, $10 \mathrm{ml}$ of buffered peptone water, BPW (Oxoid, CM0509) was added and the tubes incubated at $100 \mathrm{rpm}$ for $37^{\circ} \mathrm{C}$ for enrichment. Subsequently, $1 \mathrm{ml}$ was centrifuged for $10 \mathrm{~min}$ at $5000 \times g$ at room temperature. The supernatant was discarded and the pellet re-suspended in $1 \mathrm{ml}$ peptone-saline-solution, PSP $\left(8.5 \mathrm{~g} \mathrm{NaCl}\right.$ and $1 \mathrm{~g}$ peptone $\left./ 1 \mathrm{l} \mathrm{H}_{2} \mathrm{O}\right)$. After a further centrifugation step as previously described, the pellets were frozen at $-20{ }^{\circ} \mathrm{C}$ until used for DNAisolation. Furthermore, $1 \mathrm{ml}$ of the enrichment broth was centrifuged for $10 \mathrm{~min}$ at $5000 \times g$, the pellet resuspended in $100 \mu \mathrm{l}$ PSP and transferred to microbank cryovials (Pro-Lab Diagnostics, REF Pl. 170/R). The prepared vials were stored at $-70{ }^{\circ} \mathrm{C}$ until used for the isolation of viable EHEC-strains.

\subsection{Isolation of DNA}

DNA-isolation was performed using $1 \mathrm{ml}$ of the enrichment broth (see Sect. 2.2). The cells were processed on a QIAcube extraction robot (Qiagen, 9001293) using the DNeasy blood and tissue kit (Qiagen, 69504). The eluate of $150 \mu \mathrm{l}$ was kept at $-20{ }^{\circ} \mathrm{C}$ until qPCR was performed without further dilution.

\subsection{Real-time PCR}

Real-time PCR was performed following both ISO protocol (International Organization for Standardization 2011) and a European reference method (European Union Reference Laboratory for E. coli 2013) with the following modification: Probe wzx (O103) is listed in the ISO-method without any Tmmodifier but according to the original literature (Perelle et al. 2005), labelled with a minor groove binder, was used with the alternative Tm-modifiers propynyldeoxy (pd) C and pd U (Microsynth AG, Balgach, Switzerland). The wzx (0103) probe sequence was as follows: (FAM)-pdCApdU AGpdC pdCpdUG pdUpdUG TpdUpdU pdUAT-(BHQ1). Tests were carried out in duplicates and results with Cq-values of $>30$ considered to be negative.

\subsection{Isolation of EHEC-strains}

Based on the Cq-values generated in the screening of water samples we decided whether attempted isolation of EHEC-strains was advisable (i.e. where Cqvalues were $<30$, isolation was conducted). For each O-group, the test which revealed the lowest Cq-value (i.e. the highest target copy number) was identified and if the signals for the tested virulence factors (stx1, stx1 and eae) were clearly positive, isolation of EHECstrains was attempted. For that purpose, one microbank cryovial bead (see Sect. 2.2) was transferred into $3 \mathrm{ml}$ of BPW and incubated for $4 \mathrm{~h}$ at $37{ }^{\circ} \mathrm{C}$ in an incubation shaker at $100 \mathrm{rpm}$. Subsequently, 10 plates of enterohemolysine agar, EHLY (Oxoid, PB5105A) were inoculated with $10 \mu \mathrm{l}$ each of BPW-culture and incubated aerobically at $37{ }^{\circ} \mathrm{C}$ overnight. 50 typical 
colonies were separated into 5 pools and further analyzed as follows: cell material from a typical colony was taken with a plastic tip, first spotted on a defined area of a TBX plate (Oxoid, CM0945) and then washed out in $50 \mu \mathrm{l}$ of $\mathrm{H}_{2} \mathrm{O}$. A complete pool with cell material of 10 typical colonies was diluted 1:10 in $0.2 \times$ TE buffer and the suspension heated at $95{ }^{\circ} \mathrm{C}$ for 5 min. Finally, cell debris were sedimented by centrifugation at $20,000 \times g$ for $1 \mathrm{~min}$ and $70 \mu \mathrm{l}$ of supernatant taken for PCR analysis. From pools where fully virulent strains were suspected according to the PCR-result, all the isolates belonging to the pool were taken from the TBX plate and individually analyzed by PCR. This screening utilizing 50 colonies was performed for the O-groups 26, 103, 104, 111, 145 and 157. In one additional trial (O-group 145), 800 colonies were screened to increase the probability of a successful isolation of fully virulent EHEC-strains.

\section{Results and discussion}

\subsection{Selection of isolation procedure}

ISO/TS 13136:2011 (International Organization for Standardization 2011) defines that in the case of positive PCR-results, 50 colonies with E. coli morphology have to be screened in order to isolate EHEC strains, which might be present in a sample. Concerning the screening methodology, the ISO method allows for some variation between laboratories. We decided to use EHLY-agar developed by Beutin et al. (1996). Since typical colonies were not numerous, we trailed 3 methods to increase assay sensitivity:

1. Inoculating 10 EHLY-plates per sample

2. Combining commercial immunobeads with EHLY-agar and

3. Supplementing EHLY plates with vancomycin.

However, the yield of presumptive colonies did not increase using any of the aforementioned methods (data not shown).

\subsection{Findings of qPCR-testing}

Table 1 shows the finding of PCR-testing. Both karst sources were tested 9 times over a period of approximately 2 months. Although the sample volumes were not exactly the same (Source A: $500 \mathrm{ml}$ and source B: $1000 \mathrm{ml}$ ), a qualitative comparison is passable for two reasons. Firstly, the sample volumes differed only by factor 2 and secondly, PCR testing was done after an enrichment step in a liquid medium overnight. A notable finding was the absence of O-group 111 in both sources. A malfunction of the applied test could be excluded since the control reactions were appropriate. Also, the 0111 detection assay worked perfectly with samples from a waste water treatment plant (ARA Neubrück, Bern, approx. 380.000 population equivalent). The two investigated karst sources are located in rural areas with a considerable bovine population. A recent study in Switzerland investigating the occurrence of Shiga toxin-producing $E$. coli of the O-groups 26, 103, 111, 145 and 157 in slaughtered cattle showed that $E$. coli O111 occurred infrequently at only $0.8 \%$ (Hofer et al. 2012). The five other O-groups were detected in both sources at approximately the same frequencies. The overall frequencies for the O-groups were as follows: 026: 6/18 (33.3\%); 0157: 6/18 (33.3\%); 0104: 12/18 (66.6 \%); 0103: 13/18 (72.2\%) and 0145: 17/18 (94.4\%). As shown in Table 1, the genes for stx 1 , stx2 and eae occurred regularly in both sources. The overall frequency for stx 1 was $14 / 18(77.8 \%)$, for stx $215 / 18$ (83.3\%) and for eae 14/18 (77.8 \%).

\subsection{Isolation of EHEC-strains}

For isolation purposes, those samples with the lowest Cq-values (i.e. the highest concentrations) for the O-groups were selected under the precondition that also stx1, stx2 and eae signals were detected. For 026 , it was sample 3 of source A (Cq 21.4), for 0103 sample 4 of source A (Cq 20.8), for 0104 sample 4 of source B (Cq 21.6), for O145 sample 1 of source A (Cq 17.3) and for O157 sample 3 of source B (Cq 19.6). By screening 50 colonies as described in Sect. 2.5, we isolated on only one occasion virulent EHEC-strain 0103 (stx $1+1$ stx $2-($ eae + ). This finding clearly demonstrated that qPCR-results alone have a very limited value regarding presence of viable EHEC-strains. The two karst sources studied here represent particularly difficult and complex hydrological situations. They collect water from rather large areas, with many potential contamination sources, which are available for quick transportation owing to the high hydraulic conductivity of karst systems. In another study, it was shown that both source A and B are affected by human and ruminant (bovine) fecal contamination (Diston et al. 2016 accepted for publication). Therefore, we intensively screened sample 1 from source A (Cq-value of 17.3, O group 145) with an intention of isolating viable EHEC-strains. Despite screening 800 colonies, no virulent EHEC-strain could be isolated. 
Table 1 Real-time PCR screening of samples from two karst water sources for presence of enterohemorrhagic E. coli (EHEC) of serotypes O26, 0103, 0104, O111, 0145 and 0157

\begin{tabular}{|c|c|c|c|c|c|c|c|c|c|c|}
\hline \multirow[t]{2}{*}{ Source } & \multirow[t]{2}{*}{ Week } & \multicolumn{9}{|c|}{ qPCR-Findings (Cq-values) ${ }^{a}$} \\
\hline & & $s t \times 1$ & stx2 & eae & $\mathrm{O} 26$ & 0103 & 0104 & 0111 & 0145 & 0157 \\
\hline A & 1 & 24.9 & 22.4 & 23.8 & nd & 23.5 & 27.6 & nd & 17.3 & 29.7 \\
\hline A & 2 & 26.0 & 23.4 & 23.0 & 27.1 & 24.7 & 26.7 & nd & 20.3 & nd \\
\hline A & 3 & 22.9 & 24.0 & 20.5 & 21.4 & nd & 27.8 & nd & 20.7 & 28.0 \\
\hline A & 4 & 21.0 & 21.8 & 19.8 & nd & 20.8 & nd & nd & 21.5 & nd \\
\hline$A$ & 5 & 25.8 & nd & 21.5 & 23.8 & 20.9 & nd & nd & 19.9 & nd \\
\hline A & 6 & 21.7 & 20.0 & 23.3 & nd & nd & 23.2 & nd & 19.9 & nd \\
\hline A & 7 & 25.1 & 20.7 & 24.2 & nd & 22.0 & 26.8 & nd & 21.1 & nd \\
\hline$A$ & 8 & 21.2 & 18.5 & nd & nd & nd & nd & nd & 21.3 & 24.3 \\
\hline$A$ & 9 & nd & 22.2 & nd & nd & nd & nd & nd & 20.9 & nd \\
\hline B & 1 & 24.0 & 25.1 & 20.2 & 28.1 & 22.0 & 23.6 & nd & 22.2 & nd \\
\hline B & 2 & 25.2 & 23.6 & 20.2 & 25.7 & 22.5 & 19.4 & nd & 21.2 & nd \\
\hline B & 3 & 25.5 & 23.6 & 20.4 & 25.9 & 19.4 & 23.1 & nd & 22.6 & 19.6 \\
\hline B & 4 & 28.6 & 24.6 & 20.3 & 21.9 & 24.2 & 21.6 & nd & 23.0 & 25.2 \\
\hline B & 5 & 26.7 & 26.7 & 20.0 & nd & 20.9 & 23.7 & nd & 22.4 & nd \\
\hline B & 6 & nd & nd & 20.4 & nd & 20.2 & 24.4 & nd & 22.2 & 23.1 \\
\hline B & 7 & 25.5 & 23.4 & 23.7 & nd & 22.4 & 25.3 & nd & 22.6 & nd \\
\hline B & 8 & nd & nd & nd & nd & nd & nd & nd & nd & nd \\
\hline B & 9 & nd & 27.4 & nd & nd & 25.8 & nd & nd & 21.0 & nd \\
\hline
\end{tabular}

nd not detectable (Cq-value $>30$ )

${ }^{a}$ Mean value of double measurement

\section{Conclusions}

In the EU, official microbiological criteria (Food safety criteria) for certain EHEC serotypes in sprouts has been decreed (Eidgenössisches Departement des Innern 2014). National authorities for food control also test for EHEC in other foods than sprouts as indicated by RASFF alerts (European Commission 2014). However, the application of a microbiological criterion for EHEC can be problematic. As shown in our study, one difficulty is that the analytics are based on PCR, which limits the epidemiological explanatory power considerably. In the present study, PCR data suggested at a first glance that the examined sources are regularly contaminated with diverse serotypes of EHEC. In fact, the detected O-groups and the genes for stx 1 , stx 2 and eae probably derived from a broad variety of $E$. coli strains harboring single, but not all, traits necessary for a virulent EHEC. Even with promising screening data (low Cq-values for O-group), the screening of 50 colonies from EHLYagar, and extensive testing of 800 colonies, only once resulted in a successful isolation of a virulent EHECstrain. This finding reveals that PCR results alone allow only limited conclusions to be drawn and that the isolation of viable EHEC strains is essential. Altogether, the examination of foods for EHEC is a complicated and expensive undertaking. However, official microbiological criteria should be testable whenever possible with simple, unambiguous and cost-efficient standard methods. The latter is also important because food-producers have to carry out microbiological tests in the context of self-responsibility and self-control in order to prove that legal requirements are fulfilled. Therefore, the question is whether complicated and costly analytics such as EHEC-detection in foods should not be limited to epidemiological questions (for example outbreak investigations) and whether safety of EHEC risk products could not be pursued with simple criteria for apathogenic E. coli serving as hygiene indicators?

\section{Compliance with ethical standards}

Conflict of interest The authors declare that they have no conflict of interest.

Open Access This article is distributed under the terms of the Creative Commons Attribution 4.0 International License (http://creativecommons.org/licenses/by/4.0/), which permits unrestricted use, distribution, and reproduction in any 
medium, provided you give appropriate credit to the original author(s) and the source, provide a link to the Creative Commons license, and indicate if changes were made.

\section{References}

Beutin L, Zimmermann S, Gleier K (1996) Rapid detection and isolation of shiga-like toxin (verocytotoxin)-producing Escherichia coli by direct testing of individual enterohemolytic colonies from washed sheep blood agar plates in the VTEC-RPLA assay. J Clin Microbiol 34:2812-2814

Bundesamt für Gesundheit (2008) Gruppenerkrankungen (Ausbrüche) mit mikrobiell kontaminierten Lebensmitteln in der Schweiz, 1994-2006. BAG Bull 32:562-568

Bundesamt für Gesundheit (2015) Auffälliger Anstieg der Meldezahlen enterohämorrhagischer E.coli-Infektionen über die letzten Monate in der Schweiz: Einfluss neuer Multiplex PCR-Methoden in der Primär-Diagnostik? BAGBull 52:988-990

Diston D, Robbi R, Baumgartner A, Felleisen R (2016) Microbial source tracking in highly vulnerable karst drinking water resources. J Water Health (Manuscript accepted for publication)

Eidgenössisches Departement des Innern (2014) Hygieneverordnung des EDI (HyV, SR 817.024.1) vom 23. November 2005, (Stand am 1 Januar 2014). https://www. admin.ch/opc/de/classified-compilation/20050160/index. html

European Commission (2014) Rapid Alert System for Food and Feed (RASFF), Annual Report. http://ec.europa.eu/food/ safety/rasff/docs/rasff_annual_report_2014.pdf
European Union Reference Laboratory for E. coli (2013) Detection and identification of Verocytotoxin-producing Escherichia coli (VTEC) O104:H4 in food by Real Time PCR. http://www.iss.it/binary/vtec/cont/EU_RL_VTEC_ Method_04_Rev_1.pdf

Hofer E, Stephan R, Reist M, Zweifel C (2012) Application of a real-time PCR-based system for monitoring of O26, 0103, O111, 0145 and 0157 Shiga toxin-producing Escherichia coli in cattle at slaughter. Zoonoses Public Health 59:408-415

International Organization for Standardization (2011) Microbiology of food and animal feed-Real-time polymerase chain reaction (PCR)-based method for the detection of food-borne pathogens-Horizontal method for the detection of Shiga toxin-producing Escherichia coli (STEC) and the determination of 0157, O111, O26, 0103 and 0145 serogroups. ISO/TS 13136:2011(E)

Michino H, Araki K, Minami S, Takaya S, Sakai N, Miyazaki M, Ono A, Yanagawa H (1999) Massive outbreak of Escherichia coli 0157:H7 infection in schoolchildren in Sakai city, Japan, associated with consumption of white radish sprouts. Am J Epidemiol 150:787-796

O’Brien AD, Melton AR, Schmitt CK, Batts ML, Griffin DE (1993) Profile of Escherichia coli 0157:H7 pathogen responsible for hamburger-borne outbreak of hemorrhagic colitis and hemolytic uremic syndrome in Washington. J Clin Microbiol 31:2799-2801

Perelle S, Dilasser F, Grout J, Fach P (2005) Detection of Escherichia coli serogroup 0103 by real-time polymerase chain reaction. J Appl Microbiol 98:1162-1168

Robert Koch Institute (2011) Abschliessende Darstellung und Bewertung der epidemiologischen Erkenntnisse im EHEC O104:H4 Ausbruch, Deutschland 2011 http://edoc.rki.de/ documents/rki_ab/reeFNxULvsdZo/PDF/262b4Pk2TGGs.pdf) 